\title{
Conhecimentos tradicionais quilombolas: reflexões críticas em defesa da vida coletiva
}

Márcia Cristina Américo* Luiz Marcos de França Dias **

* (Associação Quilombo de São Pedro, Eldorado-SP, Brasil)

** (Rede Estadual de Ensino de São Paulo, Eldorado-SP, Brasil)
Resumo: Os saberes e conhecimentos das comunidades tradicionais quilombolas do Vale do Ribeira (SP) tem como base a transmissão geracional por meio da tradição oral, mantida pela memória, história e etnicidade. Tais conhecimentos permitem uma releitura dos saberes, usos e práticas que estão interligados a uma cosmovisão étnico-territorial ancestral, enquanto propositores de uma práxis revolucionária, pela segurança e autonomia à vida em territórios coletivos. A compreensão sobre a temática quilombola implica não descontextualizar o processo de resistência histórico, socioeconômico, político, cultural, ambiental e epistêmico, da dominação colonial e capitalista global. Os conhecimentos das comunidades quilombolas propõem mudanças e reflexões críticas visando a emancipação humana.

Palavras-chave: Quilombos. Território coletivo. Saberes tradicionais. Conservação da biodiversidade. 


\section{TERRITÓRIO TRADICIONAL: O PROCESSO DE AQUILOMBAMENTO}

Este ensaio tem como proposta avançar na discussão sobre a produção do conhecimento acumulado pelos povos tradicionais quilombolas localizados na região do Vale do Ribeira, nos municípios de Eldorado e divisa com Iporanga, no estado de São Paulo. Essa região possui a maior área contínua de Mata Atlântica preservada do Brasil e, desde 1999, a Organização das Nações Unidas para a Educação, a Ciências e a Cultura (Unesco) a reconhece como patrimônio natural, socioambiental e cultural da humanidade. Nesse contexto, buscamos analisar a relação que as comunidades quilombolas estabelecem com o território e como enfrentam os conflitos territoriais e ambientais na contemporaneidade, o que implica uma discussão mais ampla dentro do contexto socioeconômico, político e ambiental no sistema capitalista global. Traremos, também, a experiência do Planejamento Territorial nos Quilombos dessa região a partir do Quilombo São Pedro ${ }^{1}$.

Tendo em vista que o processo de aquilombolamento vivenciado pelas comunidades é histórico e está em constante transformação em suas múltiplas faces na colonialidade/modernidade, faz-se necessário retomar as contradições históricas e o desconhecimento da história como proposta de descolonização do conhecimento.

O conceito de aquilombamento remete aos conflitos e ações sociais, práticas e políticas ininterruptas pela existência, vivenciados pelas diferentes gerações que estão diante do antagonismo do reconhecimento da humanidade e das contradições sistêmicas ao longo dos séculos. Os conflitos pelo direito de não somente sobreviver, mas o de existir em plenitude - são organizados e reivindicados em defesa da existência física, cultural, histórica e social das comunidades quilombolas. Existir e resistir se estabelecem dentro de um movimento intrincado à coletividade, aos laços que interligam os quilombolas que dividem espaço geográfico e político em comum, movimento mais amplo que conecta as distintas comunidades do Brasil (SOUZA, 2016, p. 123).

Acompreensão do processo de aquilombamento das comunidades quilombolas no Brasil, ao delimitarmos a história do capitalismo e da modernidade/ colonialidade, tem sua origem no período da colonização/escravização eurocêntrica nos países colonizados da África a partir do século XV, período em que se instaurou naquele continente e também nas Américas um estado de

\footnotetext{
Ver em: PASINATO, Raquel. Planejamento territorial participativo: relato de experiências em comunidades quilombolas do Vale do Ribeira/SP. São Paulo: Instituto Socioambiental, 2012
} 
servidão, coerção física e psicológica e desigualdades econômicas, de raças e de gênero. Os povos originários e africanos foram submetidos à ideologia do conceito raça e sub-raças e a condições sub-humanos.

Aníbal Quijano, ao abordar os efeitos da colonialidade do poder na América Latina, aponta que um dos eixos "fundamentais do padrão de poder é a classificação da população mundial de acordo com a ideia de raça”, uma construção social que exprime a experiência elementar da dominação colonial que está imbricada nas estruturas mais importantes da dominação do poder mundial, que inclui a sua racionalidade específica - o eurocentrismo (QUIJANO, 2005, p. 227).

O conceito raça empregado ainda nos dias de hoje não é biológico, mas, sim, um conceito ideológico que esconde a relação de poder e de dominação que tem se imposto nas Américas e no mundo, operando sistematicamente na divisão do trabalho. "[Os conceitos de] Raça e divisão do trabalho foram estruturalmente associados e reforçados mutuamente, apesar de que nenhum dos dois era necessariamente dependente do outro para existir ou para transformar-se” (QUIJANO, 2005, p. 231 apud GOMES, 2010, p. 730).

Algumas categorias regem a sociedade brasileira: cultural, política, social, econômica e racial - esta última intrinsecamente ligada à relação de poder (CUNHA JÚNIOR, 2007, p. 75) e, na forma de racismo, determinante para a manutenção e reprodução das desigualdades econômicas, política e social. 0 racismo deixa de ser um problema apenas conjuntural, "episódio das relações interpessoais", e passa a ser um problema estrutural. Dessa forma, políticas públicas de ações afirmativas podem interferir diretamente nas relações de poder (CUNHA JÚNIOR, 2007, p. 73).

O conceito raça foi fundamental no colonialismo e continua sendo na modernidade/colonialidade enquanto estrutural e estruturante nas relações de poder. Os conflitos e resistências dos povos africanos e seus descendentes nas Américas se inscrevem dentro do contexto da desterritorialização e desenraizamento dos povos africanos na África em sua diáspora às Américas no sistema de dominação e colonização europeia. 0 enfrentamento para a ressignificação da vida desses povos esteve pautado no direito à liberdade e à dignidade humana.

$\mathrm{Na}$ modernidade/colonialidade, a ressignificação e o reconhecimento do território ocupado pelos quilombolas estão intimamente ligados ao desenraizamento e enraizamento, pertencimento étnico e ancestral e 
ressignificação do território ao qual foram submetidos historicamente pelo colonialismo ocidental. Os conflitos se dão pelo direto à reparação histórica e o território faz parte da história ancestral, que é a condição para a produção dos próprios meios de subsistência e à manutenção da própria cultura e tradições.

O direito ao território ocupado pelos povos tradicionais, categoria em que se inserem as comunidades quilombolas, está assegurado na Constituição Federal de 1988 (BRASIL, 1988), porém, a inserção na lei máxima do país não é garantia de que na prática tal direito esteja sendo efetivamente respeitado. Entende-se por povos tradicionais

Povos ou grupos que vivendo em áreas periféricas à nossa sociedade, em situação de relativo isolamento face ao mundo ocidental, capitalista, construíram formas de se relacionar entre si e com os seres e coisas da natureza muito diferente das formas vigentes na nossa sociedade (ESTERCI, 2008, p. 233).

O enfrentamento das comunidades quilombolas está atrelado ao entrave político e jurídico em uma outra perspectiva que se distancia do projeto desenvolvimentista moderno e capitalista. A disputa pelas terras de quilombos no Vale do Ribeira, no estado de São Paulo, por exemplo, ao longo da história tem envolvido vários grupos de interesse, como grileiros, posseiros, fazendeiros, instituições públicas governamentais e empresas privadas. Para os quilombolas, a terra é considerada um bem comum para a manutenção da vida coletiva das famílias - contrapõe-se à lógica de mercado e consumo. 0 projeto de vida das comunidades se insere na reafirmação e reconhecimento coletivo do território étnico e seus modos específicos de organizar a vida em consonância ecológica, cultural, social, ancestral - nessa compreensão, a natureza e o humano não se dissociam.

\section{Quilombos no Vale do Ribeira - Estado de SÃo Paulo}

A Fundação Cultural Palmares aponta a existência² de 3.524 comunidades quilombolas no país, mas não descarta que esse número possa chegar a 5 mil, segundo pontua também a Coordenação Nacional de Articulação das Comunidades Negras Rurais Quilombolas (Conaq³). Utilizaremos a estatística

Disponível em: http://www.palmares.gov.br/?p=3041. Acesso em: 15 jan. 2019.

3 A Coordenação Nacional de Articulação das Comunidades Negras Rurais Quilombolas (Conaq) é o órgão representativo das comunidades em nível nacional. Ela organiza-se por meio de representações locais e estaduais, tendo ainda uma coordenação nacional, responsável por dialogar com o governo federal e outras instituições. 
da Conaq como referência por serem os dados e informações obtidos do movimento social composto pelos membros quilombolas das comunidades do Vale do Ribeira, já que a identificação das comunidades quilombolas e encaminhamentos jurídicos por reconhecimento legal ocorrem primeiro a partir das organizações quilombolas (nos âmbitos local e nacional).

O Vale do Ribeira, em sua parte que se situa no estado de São Paulo, possui uma área de 1.711 .533 hectares e é formado por 23 municípios. É uma região com imenso valor cultural e ambiental, por possuir uma vasta extensão florestada de Mata Atlântica, compreendendo várias unidades de áreas protegidas por parques e reservas e um litoral de paisagens diversas. Agrega a riqueza e a beleza da diversidade cultural de povos indígenas, caiçaras, quilombolas e ribeirinhos. Também encontramos no vale grupos migrantes do Nordeste e comunidades remanescentes de programas governamentais de colonização, como a japonesa, a francesa, a suíça e a alemã, entre outras (DIEGUES, 2007, p. 2).

A Equipe de Articulações das Comunidades Negras do Vale do Ribeira (Eaacone) contabiliza 57 comunidades quilombolas, somando aproximadamente 10 mil

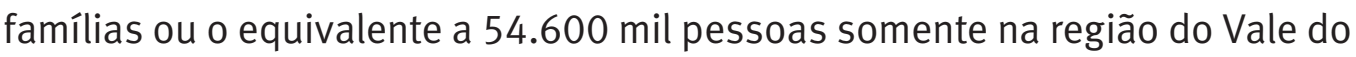
Ribeira. Algumas comunidades estão em fase de reconhecimento.

No município de Eldorado-SP encontram-se 14 comunidades quilombolas: André Lopes, Ivaporunduva, Sapatu, Pedro Cubas, Pedro Cubas de Cima, Poça, Abobral Margem Direita, Abobral Margem Esquerda, Bananal Pequeno, Engenho, Galvão, Ostra, Nhunguara e São Pedro. Essas últimas três comunidades se dividem entre os municípios de Eldorado e Iporanga. 0 acesso à região é pela Rodovia Régis Bittencourt (BR-116).

O Quilombo São Pedro e as comunidades vizinhas dos municípios de Eldorado e Iporanga-SP estão inseridos em Zona de Vida Silvestre e Área de Proteção Permanente e Reserva Legal (RL) da Serra do Mar (APPs), que compõe a Mata Atlântica, algumas com sobreposição do Parque Estadual Intervales. A comunidade é composta por 46 famílias com aproximadamente 150 pessoas. Organizam-se por meio da associação de moradores que foi criada em 1980, e as tomadas de decisão se dão de forma coletiva, no que se refere à organização social e territorial das famílias. 0 contexto histórico da formação da Associação Quilombo São Pedro, pioneira nesse tipo de organização entre as comunidades da região, e das associações de moradores das comunidades quilombolas do Vale do Ribeira, de forma geral, está atrelado à defesa do território, após conflitos fundiários, bem como à luta pela garantia 
do direito à terra e fixação do trabalhador e trabalhadora do campo, desde a década de 1970. Ao iniciá-la pela posse da terra, na década de 1980, simultaneamente iniciou-se também o trabalho das comunidades nas ações e movimentos políticos contra a construção de barragens, estrategicamente, para fortalecimento político e social. Foi criada a Equipe de Articulação e Assessoria às Comunidades Negras (Eaacone) e o Movimento dos Ameaçados por Barragens (Moab), compostos pelos quilombolas na região do Vale do Ribeira.

Na década de 1990, o governo federal aprovou o estudo de inventário hidrelétrico que previa a construção de quatro barragens: Tijuco Alto, Itaoca, Funil e Batatal, ao longo do rio Ribeira de Iguape ${ }^{4}$. Com a construção das barragens, cerca de 11 mil hectares de área seriam inundados e seria inevitável o desaparecimento das terras de quilombos e pequenos agricultores, cavernas, unidades de conservação e cidades (AMÉRICO, 2015, p. 50).

No final da década de 1980 e início de 1990, as comunidades se organizaram contra as desapropriações de suas terras e a aprovação do projeto de hidroelétricas. Várias manifestações ocorreram em diferentes lugares públicos e privados 5 . Os atos e a demora exigida no processo de aprovação de quatro grandes empreendimentos junto aos órgãos ambientais levaram a Companhia Brasileira de Alumínio (CBA), principal interessada, a focar somente o projeto UHE Tijuco Alto. Então, no dia 4 de novembro de $2016^{6}$, após quase três décadas, por meio de manifestações e articulações políticas e sociais, o Instituto Brasileiro do Meio Ambiente e dos Recursos Naturais Renováveis (Ibama) indeferiu a solicitação de licenciamento do empreendimento por sua

4 A Usina Hidrelétrica de Tijuco Alto (UHE Tijuco Alto) seria um empreendimento planejado pela Companhia Brasileira de Alumínio (CBA), uma das empresas do Grupo Votorantim, para aumentar a oferta de energia elétrica para seu complexo metalúrgico localizado na cidade de Alumínio, antiga Mairinque, no interior de São Paulo. A localização da UHE Tijuco Alto estava prevista para o alto curso do rio Ribeira de Iguape, na divisa dos estados de São Paulo e Paraná, cerca de 10 km a montante das cidades de Ribeira (SP) e Adrianópolis (PR), e a aproximadamente 333 km de sua foz, no complexo EstuarinoLagunar de Iguape-Cananeia-Paranaguá.

5 As manifestações ocorreram e ainda ocorrem em diferentes lugares, desde os anos 1990. Protagonizadas por comunidades ameaçadas pelas barragens (caiçaras, indígenas, quilombolas e ribeirinhos) e organizações que apoiam o movimento social, como o Partido dos Trabalhadores (PT), Movimento dos Trabalhadores Rurais Sem Terra (MST), Conaq, Eaacone, Moab, Movimento dos Atingidos por Barragens (MAB), Instituto Socioambiental (ISA) e ambientalistas. Ver em: https://www.socioambiental.org/pt-br/ noticias-socioambientais/populacao-do-vale-do-ribeira-esta-livre-de-tijuco-alto.

6 Disponível em: https://www.socioambiental.org/pt-br/noticias-socioambientais/ populacao-do-vale-do-ribeira-esta-livre-de-tijuco-alto. Acesso em: 22 jan. 2019. 
inviabilidade ambiental, pontuando que:

[...] o processo de licenciamento da UHE Tijuco Alto recebe forte pressão popular contrária à implantação do empreendimento, com dezenas de notas de repúdio ao projeto $e$ recomendações de diversas entidades sociais e do Ministério Público para a não construção do empreendimento. Tais manifestações abordam principalmente a relevância socioambiental da área potencialmente afetada pelo empreendimento, bem como a presença expressiva de comunidades tradicionais e quilombolas que eventualmente seriam afetadas pela UHE (MINISTÉRIO DO MEIO AMBIENTE, 2016) . ${ }^{7}$

Com o soterramento desse projeto, novas propostas de empreendimentos voltam a ameaçar as comunidades: as Pequenas Centrais Hidrelétricas (PCHs), planejadas para a região, que por serem de menor porte, não necessitam de processos longos e burocráticos para licenciamento. Nesse sentido, as comunidades continuam mobilizadas, visando a não implementação de novos empreendimentos, que afetam os modos de vida e as relações com a Mata Atlântica.

\section{O TERRITÓRIO COMO FONTE DE VIDA}

As relações das famílias quilombolas com o território estão interligadas às decisões coletivas do uso da terra e de seus recursos naturais, envolvendo a colheita e o plantio dos alimentos; o puxirão ${ }^{8}$; a edificação da casa de pau a pique; as práticas da cura por meio das plantas medicinais que envolvem reza e benzimento; as festas religiosas, em que elementos da natureza essenciais à vida, como terra, água e os alimentos, são reverenciados; e, por fim, a organização comunitária e ações práticas, sociais e jurídicas para a manutenção da vida em seus territórios.

O Decreto Federal 4.887/2003, em seu Artigo 2ํㅜㄹ, reconhece a terra como bem comum à manutenção da vida. Esse dispositivo define que "São terras

Despacho 02001.024695/2016-14-Dilic/Ibama, da Diretoria de Licenciamento Ambiental/ Ibama, que dispõe o indeferimento do pedido de licença prévia para a UHE Tijuco Alto - Processo 02001.001172/2004-58. Disponivel em: https://www.socioambiental.org/ sites/blog.socioambiental.org/files/nsa/arquivos/document.pdf. Acesso em: 10 maio 2019.

8 O puxirão refere-se ao mutirão. São os encontros das famílias em que se reúnem quilombolas do próprio território e dos quilombos vizinhos para a realização do trabalho coletivo de plantação de arroz, feijão, construção das casas de pau a pique, entre outros. Após o trabalho, ocorre o baile do puxirão, manifestação cultural que se dá por meio da dança da cobrinha, mão esquerda e cana verde, interligadas à prática do trabalho coletivo. Ver entrevista com Luiz Marcos de França Dias [Quilombos resistem], concedida ao portal UOLTab. Disponível em: https://tab.uol.com.br/quilombos. Acesso em: 29 out. 2017. 
ocupadas por remanescentes das comunidades dos quilombos as utilizadas para a garantia de sua reprodução física, social, econômica e cultural”.

No Quilombo São Pedro e comunidades vizinhas, as principais fontes de alimentação e trabalho são advindas das roças de subsistência, inseridas no Sistema Agrícola Tradicional Quilombola (SATQ). Esse sistema se constitui de saberes, práticas, valores e relações ancestrais, de origem indígena e africana, acumulados e transmitidos oralmente ao longo das gerações, tendo como base a roça de coivara, que consiste na supressão da vegetação nativa, utilização e manejo do fogo ${ }^{9}$, plantio e posterior abandono da área após a colheita, promovendo a regeneração da floresta. Nesse sistema, as cinzas ajudam na correção do solo e os restos de vegetação, como galhos mais grossos, entram em decomposição, contribuindo para a adubação e fertilização das sementes. Esses conhecimentos da roça tradicional perpassam pela escolha do tipo de área, solo e vegetação; fases da lua; técnicas de plantio e cultivo; salvaguarda e troca das sementes crioulas e a prática do puxirão ${ }^{10}$, numa relação de mais de 300 anos em que homens e mulheres são integrantes do território em sua totalidade. Sendo base da produção da vida nas comunidades quilombolas, ela garante a segurança alimentar, o trabalho e a renda, a fixação das famílias no território e a consequente manutenção da cultura, da historicidade e da etnicidade; é uma forma de conservação da Mata Atlântica (ANDRADE; TATTO, 2013; RIBEIRO FILHO, 2016).

Pesquisas científicas recentes comprovam que a roça de coivara contribui para a conservação da floresta (PEDROSO JUNIOR et al., 2008; ADAMS, 2014; RIBEIRO FILHO, 2015 $5^{11}$, da mesma forma que dispositivos legais federais como o Sistema Nacional de Unidades de Conservação (Snuc), o Código Florestal e a Lei da Mata Atlântica, que, mesmo com algumas limitações, reconhecem a prática da coivara como direito ao modo de vida tradicional ${ }^{12}$.

9 Diferente das queimadas em larga escala, utilizadas em grandes fazendas, na roça de coivara o fogo é utilizado somente na área roçada, controlado por aceiro, não sendo permitida a invasão da floresta.

10 Ver nota de rodapé n. 9.

${ }^{11}$ Ver mais no Dossiê Sistema Agrícola Tradicional Quilombola do Vale do RibeiraSP. O compilado, que conta com dois volumes, se ancora nos conhecimentos das comunidades quilombolas, bem como em pesquisas científicas, para a solicitação do registro do sistema no Iphan como patrimônio do Brasil. Disponível em: https:// acervo.socioambiental.org/acervo/documentos/dossie-sistema-agricola-tradicionalquilombola-do-vale-do-ribeira-sp-vol-1. Acesso em: 18 maio 2019.

12 Lei da Mata Atlântica - Lei Federal 11.428/2006, regulamentada pelo Decreto 6.660/2008; Sistema Nacional de Unidades de Conservação (Snuc) - Lei 9.985/2000. Novo Código Florestal - Lei 12.651, de 25 de maio de 2012. 
Em setembro de 2018, o Instituto do Patrimônio Histórico e Artístico Nacional (Iphan) reconhece o Sistema Agrícola Tradicional Quilombola do Vale do Ribeira (SATQ) como patrimônio cultural imaterial do Brasil. Na contramão dessas considerações, as comunidades vivenciam a dificuldade da obtenção de licença para fazer as roças de coivara, ocasionada pelas interpretações equivocadas das legislações ambientais que criminalizam as práticas agrícolas tradicionais, entendendo que essas provocam o desmatamento da floresta, desconsiderando o processo de abandono das áreas para a regeneração, diferente da exploração e ocupação permanente do solo nos moldes do sistema capitalista, tendo como foco a monocultura, visando o mercado e o consumo. Junto com a ausência de técnicos necessários para a realização dos trabalhos, justificada pelos órgãos responsáveis, a emissão das autorizações já chegou a atrasar até seis anos. Hayama (2017, p. 87) explica que

A política ambiental clássica se confronta com direitos sociais e étnico-culturais, protagonizando episódios de injustiça e de racismo ambientais. Predominam, no campo da ecologia ortodoxa, posições preservacionistas e conservacionistas, as quais, preocupadas com a tutela da biodiversidade, consideram a ação humana sempre negativa e perturbadora.

Ocorre que tal morosidade por parte do estado ocasiona a perda da época de plantio, acarretando, muitas vezes, a perda das sementes, guardadas de um ano para outro, colocando em risco não só a segurança alimentar das famílias, mas todas as manifestações ligadas à roça de coivara, integrantes do SATQ.

Nos municípios de Eldorado e Iporanga há comunidades que fazem parte da Área de Proteção Ambiental Quilombos do Médio Ribeira ${ }^{13}$, que recentemente esperaram cerca de 18 meses para receber as autorizações, oriundas de processos de responsabilidade da Fundação Florestal e do Instituto de Terras do Estado de São Paulo (Itesp) ${ }^{14}$. Porém, mesmo em comunidades que não têm unidades de conservação sobrepostas ao território, a morosidade do processo é a mesma. É o caso do Quilombo Morro Seco, no município de Iguape, que deveria obter o licenciamento por parte do Itesp, mas não o recebe há dois anos, tendo somente a informação de que os documentos não serão expedidos. Por

${ }_{13}$ Disponível em: http://fflorestal.sp.gov.br/quilombos-ribeira/home/. Acesso em: 12 maio 2019.

14 A Fundação Instituto de Terras do Estado de São Paulo (Itesp) é responsável pela demarcação e regularização fundiária das terras quilombolas no estado de São Paulo. É um órgão vinculado à Secretaria da Justiça e da Defesa da Cidadania. Esses órgãos governamentais têm como proposta assegurar a proteção dos direitos constitucionais e apoiar as ações políticas, culturais, sociais e econômicas das comunidades quilombolas, comunidades tradicionais de matriz africana e povos de cultura cigana com outros ministérios e secretarias dos órgãos federais, estaduais e municipais. 
outro lado, as comunidades mantêm suas táticas de resistência às políticas que ofendem a dignidade humana por meio de mobilizações como a Feira de Troca de sementes e mudas tradicionais de quilombos do Vale do Ribeira ${ }^{15}$, 0 apoio a pesquisas que fundamentem e demonstrem a importância da roça e mobilizações ${ }^{16}$ com a finalidade de pressionar o governo quanto à criação de legislação ${ }^{17}$ que respeite o modo de vida de tais povos.

15 A Feira de Troca de sementes e mudas tradicionais das comunidades quilombolas do Vale do Ribeira, que ocorre anualmente, é um dos eventos mais significativos para as comunidades da região por promover o resgate, a manutenção e salvaguarda das sementes e mudas crioulas que corriam o risco de desaparecer. Em 2019 ocorrerá sua $12^{a}$ edição e contará também com a participação de comunidades indígenas, caiçaras, ribeirinhos e caboclos de diferentes regiões do país. Disponível em: https://www. socioambiental.org/pt-br/blog/blog-do-vale-do-ribeira/quilombos-do-vale-do-ribeirasp-festejam-dias-17-e-18-de-agosto-sua-11a-feira-de-sementes. Acesso em: 12 maio 2019.

16 No final da década de 1990, algumas comunidades que ainda não o haviam feito fundaram associações para exigir licenciamento ambiental para fazer as roças tradicionais (ANDRADE; TATTO, 2013, p. 370). No ano de 2006, preocupadas com a perda das sementes e mudas por não fazerem as roças, as comunidades, apoiadas por organizações parceiras, iniciaram as discussões para a criação de um paiol de sementes para salvaguardá-las. Em 2008, as comunidades incluem na Agenda Socioambiental Quilombola como demanda de extrema prioridade a solicitação de licenciamento ambiental, ano que marca um período de mais de meia década sem licenças, que só voltaram a ser emitidas em 2013, após resultados de estudos e várias solicitações serem encaminhados aos órgãos responsáveis pela liberação das roças em áreas férteis e essenciais para o plantio. No mesmo ano, Moab, Eaacone e comunidades apresentaram abaixo-assinado dirigido à então presidente Dilma Rousseff e ao então governador de São Paulo, Geraldo Alckmin, solicitando providências em relação à morosidade do Estado quanto à demarcação dos territórios quilombolas, o que até os dias atuais tem ocasionado ataques e assassinatos de lideranças quilombolas, por parte de terceiros que ocupam irregularmente os territórios. Nos últimos anos, as comunidades da região têm intensificado a luta pelo direito à roça, conseguindo, em 2018, o reconhecimento do SATQ como patrimônio brasileiro, pelo Iphan. Disponivel em: https://www. socioambiental.org/pt-br/noticias-socioambientais/ta-na-hora-da-roca-campanhapede-respeito-ao-plantio-tradicional-quilombola; https://www.socioambiental.org/ pt-br/blog/blog-do-vale-do-ribeira/quilombolas-do-vale-do-ribeira-discutem-criacaode-banco-de-sementes-tradicionais; https://www.socioambiental.org/pt-br/noticiassocioambientais/manifesto-pede-ao-governo-a-regularizacao-fundiaria-no-vale-doribeira; https://www.socioambiental.org/pt-br/noticias-socioambientais/quilombosdo-ribeira-recebem-autorizacao-para-fazer-suas-rocas-tradicionais. Acesso em: 10 maio 2018.

${ }_{17}$ Entre os anos de 2016 e 2018, as comunidades quilombolas, organizações e instituições parceiras como o Instituto Socioambiental, Eaacone e Moab realizaram discussões com órgãos ambientais com a finalidade de criar legislação que considerasse a prática tradicional das roças de coivara. Em 2018, após a campanha "Tá na hora da roça", que contou com mais de 7.500 assinaturas, foi publicada a resolução SMA n. 189, de 
Diegues (2008, p. 16) afirma que os modos de vida de muitas comunidades tradicionais, seus conhecimentos e práticas culturais, contribuíram e contribuem para a manutenção da biodiversidade. 0 autor explica que não existe cadastro oficial de comunidades tradicionais que ocupem unidades de conservação integral que não tenham problemas fundiários e de limitações; ele anuncia e denuncia o conservacionismo nos discursos existentes em algumas organizações não governamentais, ao se tratar de áreas de preservação ambiental de onde os povos locais são expulsos ou onde têm seu modo de vida tradicional limitado e/ou extinto pelas restrições ambientais. Diegues, citando Mark Dowie, afirma que "se quisermos proteger a biodiversidade em todos os lugares do mundo, frequentemente ocupados por povos nativos de forma ainda ecologicamente sustentável, a história nos mostra que a coisa menos inteligente a fazer é expulsá-los de suas terras” (DIEGUES, 2008, p. 20).

Com relação ao conceito de "conservação da natureza", entendemos junto com Diegues que:

\footnotetext{
"Conservação de natureza" não é somente um tema naturalista de proteção de natureza "selvagem e intocada", mas também um tema social, cultural e político; há necessidade de se incorporar as ciências sociais e os saberes tradicionais na definição e políticas conservacionistas. Daí a necessidade de um enfoque interdisciplinar para o trato do tema, que incorpore também o conhecimento local, pois ainda hoje a conservação é amplamente dominada pelas ciências naturais (DIEGUES, 2008, p. 17).
}

Hayama (2017), em sua pesquisa "Unidades de conservação em territórios quilombolas: conflitos socioambientais e atuação da defensoria pública", tendo como foco as comunidades quilombolas do Vale do Ribeira, explica que o mito moderno da natureza intocada é dominante no imaginário social e no senso comum ambiental. Ele analisa que as políticas ambientais têm uma visão preservacionista, hegemônica, eurocêntrica, arrogante e racista, as quais não consideram os povos quilombolas vinculados aos seus territórios. A partir de 1980, as comunidades tradicionais têm combatido o racismo ambiental que consiste em

20 de dezembro de 2018, que "Estabelece critérios e procedimentos para exploração sustentável de espécies nativas do Brasil no Estado de São Paulo”. Em seu Art. 2º inciso V, compreende as Atividades Tradicionais Sustentáveis como aquelas “desenvolvidas a partir de técnicas tradicionais de cultivo agrícola e exploração de espécies nativas do Brasil, tais como obtenção de matéria-prima para artesanato, construção de canoas e moradias, roça itinerante, coivara e roça de toco, incluindo-se as técnicas de agrofloresta, sem uso de agrotóxicos, fertilizantes artificiais e organismos geneticamente modificados". Disponível em: https://peticoes.socioambiental.org/ta-na-hora-da-roca. Acesso em: 15 maio 2018. 
[...] injustiças sociais e ambientais que recaem de forma desproporcional sobre etnias vulnerabilizadas. [...] O Racismo Ambiental não se configura apenas através de ações que tenham uma intenção racista, mas igualmente através de ações que tenham impacto racial, não obstante a intenção que lhes tenha dado origem. Não usamos o termo "etnias vulnerabilizadas"

por acaso, na nossa definição. Estamos, de um lado, combatendo o racismo, mas, de outro, recusando a noção de "raça", no que diz respeito a seres humanos. Fazemos questão de estabelecer de forma inquestionável que essas "etnias" compreendem mais que as populações negras, a começar pelos povos indígenas, "donos" originais deste território e submetidos a um verdadeiro genocídio (PACHECO, 2007 apud HAYAMA, 2017, p. 65).

Entre os anos de 2006 e 2010, a Associação Quilombo São Pedro, representando as famílias quilombolas da comunidade, junto a outras entidades e instituições ambientais parceiras, se organizaram para discutir e propor mudanças na legislação ambiental visando a segurança alimentar e a vida das comunidades em seus territórios. Participaram desse processo os técnicos das organizações públicas (Itesp, DEPRN, Cetesb) ${ }^{18}$, pesquisadores de universidades, tendo como resultado a aprovação, em 30 de março de 2010, da Resolução SMA-027/2010, garantindo a licença para suas atividades das roças tradicionais ${ }^{19}$.

Nesse contexto, as lideranças quilombolas traçam estratégias com base no fortalecimento para legalização dos territórios coletivos, conservação da natureza a partir da cosmovisão ancestral e tradicional, discutem a segurança alimentar, a redução do êxodo rural como única alternativa de trabalho e renda, a ocupação de terceiros no território e o futuro das gerações vindouras.

18 Departamento Estadual de Recursos Naturais (DEPRN), que foi incorporado à Companhia Ambiental do Estado de São Paulo (Cetesb), uma agência do governo do estado de São Paulo responsável pelo controle, fiscalização, monitoramento e licenciamento de atividades geradoras de poluição.

Dispõe sobre os procedimentos implicados de autorização para supressão de vegetação nativa, a que se referem os artigos 33 e 34 do Decreto Federal 6.660, de 21 de novembro de 2008, para pequenos produtores rurais e populações tradicionais visando a agricultura sustentável nas áreas de regeneração inicial da Mata Atlântica e dá outras providências. Essa resolução atende todas as comunidades tradicionais do estado de São Paulo, que podem obter licenças para suas roças tradicionais. Instituto Socioambiental (ISA, 2012, p. 5). 
4. CONFLITOS SOCIOAMBIENTAIS E O PROCESSO DE RESISTÊNCIA FUNDIÁRIA NA AMÉRICA LATINA

Desde a década de 1970, as comunidades quilombolas que compõem e participam dos movimentos sociais elaboram "proposta política-epistêmica" a partir de suas práticas e valores, que se fundamentam numa cosmovisão própria - com base em outra concepção de desenvolvimento. Elas buscam o reconhecimento e a legalização de suas terras enquanto territórios coletivos, se contrapõem ao poder público e privado contra a expansão da monocultura, a exploração dos minérios, as políticas públicas e a legislação ambiental excludentes de âmbitos regional, estadual e nacional, que coíbem o direito à terra e a segurança alimentar que sustenta a produção da vida em seus territórios coletivos.

As questões fundiárias são características de luta histórica e política comum das comunidades quilombolas não só do Brasil. Elas estão presentes na legislação nacional de alguns países da América Latina, como Colômbia, que foi o primeiro país a instituir o direito às terras dos afro-colombianos em sua Constituição, em 1991, regulamentado em 1997; e Equador, cuja legislação já em 1988 reconhecia aos afro-equatorianos os direitos coletivos as suas terras ancestrais, ratificados na nova Constituição de $2008^{20}$. Tais direitos nas legislações nacionais dos países latino-americanos não significa que de fato tenham sido efetivados, pois até os dias atuais a titulação das terras coletivas das comunidades tradicionais tem representado um entrave para os governos estatal-empresariais (DUTRA, 2011, p. 20).

No Brasil, o direito à propriedade das terras de quilombos está garantido pela Constituição Federal de 1988, nos artigos de n. 68, 215 e 216. 0 artigo 68 prevê que “Aos Remanescentes das Comunidades dos Quilombos que estejam ocupando suas terras, é reconhecida a propriedade definitiva, devendo o Estado emitir-lhes os respectivos títulos". Garante também os direitos culturais, definindo como responsabilidade do Estado a proteção das "manifestações das culturas populares, indígenas e afrodescendentes”. Já o artigo 215 afirma que "o Estado protegerá as manifestações das culturas populares, indígenas, afro-brasileiras e de outros grupos participantes do processo civilizatório nacional"; e, por fim, o artigo 216 estabelece que: "Ficam tombados todos os documentos e os sítios detentores de reminiscências" (CNE, 2011, p. 20).

20 Essas comunidades estão em países que foram colonizados pela Espanha, os chamados cimarrónes; em Cuba e na Colômbia, os palenques; na Venezuela, os cumbes; e na Jamaica, nas Guianas e nos Estados Unidos, os moroons; além de Equador, Suriname, Honduras, Belize, Nicarágua, Chile, Peru, Bolívia, Haiti e em outros territórios da América (RATTS, 2012). 
Considerando que o país manteve regime de escravização da população negra até o ano de 1888 e que o primeiro dispositivo legal de reparação histórica e reconhecimento desse povo só ocorre em 1988, com a Constituição Federal, após quase 300 anos de escravização, temos, então, exatos 100 anos de atraso no reconhecimento e garantia de direitos dessa parcela da população brasileira. Se for observado que o país possui, segundo a Conaq, mais de 5 mil comunidades quilombolas e, dessas, apenas 168 têm título de propriedade e posse ${ }^{21}$, com 29 anos da promulgação da Constituição Federal, temos em média cinco comunidades regularizadas por ano, o que levaria mais de 800 anos para definitivamente garantir políticas públicas propostas no artigo 68 da lei máxima deste país.

Os reflexos desse atraso na implementação de políticas compensatórias visando a população negra se acentuam não só no campo dos conflitos territoriais voltados às comunidades quilombolas, mas também no que tange às áreas periféricas do país. O Atlas da Violência 2017 analisou as taxas de homicídio entre os anos de 2010 e 2015 em municípios com mais de 100 mil habitantes ${ }^{22}$. Tal estudo aponta que de cada 100 pessoas assassinadas no país, 71 são negras; além disso, constata-se, ainda, que o assassinato de jovens do sexo masculino com faixa etária entre 15 e 19 anos é quase $48 \%$ do total dos óbitos registrados no período, sendo que nessa mesma faixa jovens negros estão mais vulneráveis a homicídio. Segundo o estudo, o índice de jovens negros assassinados teve um aumento de mais de $18 \%$, se comparado aos últimos estudos, enquanto o mesmo índice teve uma redução de 12,2\% se considerados somente jovens não negros.

Em contraponto a esses dados, o Movimento Quilombola, apoiado pelo Movimento Negro, traz as políticas públicas como expressões das práxis revolucionárias sociais, políticas e jurídicas reivindicatórias das famílias e lideranças quilombolas que compõem os movimentos sociais quilombolas e entidades que os apoiam em todas as áreas emergentes: terra, educação, saúde, trabalho, renda, acesso, entre outros.

Entre os anos de 1988 e 2004 várias leis e dispositivos reconhecem os quilombolas enquanto sujeitos de direito. Políticas públicas foram sendo efetivadas visando a reparação histórica da marginalização e da extrema

${ }^{21}$ Ver em: Comissão Pró-Índio de São Paulo, 2017. Disponível em: http://www.cpisp.org.br/ terras/html/por_que_as_titulacoes_nao_acontecem.aspx. Acesso em: 27 ago. 2018.

22 Ver em: Instituto de Pesquisa Econômica Aplicada (IPEA). Atlas da Violência. Disponível em: http://ipea.gov.br/atlasviolencia/. Acesso em: 27 ago. 2017. 
pobreza em que atualmente $75 \%$ dos quilombolas foram inseridos desde 0 período escravagista/colonial e mantidos no sistema capitalista pós-colonial.

O reconhecimento das terras quilombolas está intimamente ligado à produção de vida e gerou uma discussão mais ampla em nível nacional e internacional para efetivação dos direitos. A convenção 169 da Organização Internacional do Trabalho (OIT) sobre os Povos Indígenas e Tribais, homologada pelo Decreto n. 5.051, de 19 de abril de 2004, e pelo Decreto n. 6.040, de 7 de fevereiro de 2007, instituiu a Política Nacional de Desenvolvimento Sustentável aos povos e comunidades tradicionais. Os acordos e tratados assinados no Brasil determinam para os povos e comunidades tradicionais a proteção jurídica e específica sobre os territórios tradicionais como espaços necessários à reprodução cultural, social e econômica, sejam eles utilizados de forma permanente, seja de forma temporária (CNE, 2011, p. 13).

Desde o ano de 2004, as comunidades quilombolas, dentro dos movimentos sociais e entidades parceiras, tiveram de se organizar contra a Ação Direta de Inconstitucionalidade (ADI) 3239/2004²3, ajuizada pelo Partido da Frente Liberal (PFL), atual Partido Democrata (DEM). A ação, que só foi julgada como improcedente no ano de 2018, questionava a regulamentação das terras coletivas dos quilombos prevista no Decreto 4.887/2003. Tal decreto foi uma das maiores conquistas dos últimos anos, fruto da luta dos movimentos quilombola e social. Ele não só regulamenta o artigo 68 do Ato das Disposições Constitucionais Transitórias (ADCT), como também serve de base para a elaboração de políticas públicas para quilombos no país.

O quilombola Denildo Rodrigues de Moraes, liderança quilombola de Ivaporunduva e coordenador da Conaq, aponta para a seguinte questão:

Só a Medida Provisória 759, recentemente sancionada pelo presidente Temer, pode regularizar de uma vez 2.376 terras públicas invadidas. É praticamente a institucionalização da grilagem de terras. São 4,3 milhões de hectares, o que dá quase um Estado do Rio de Janeiro. Os quilombos também estão na alça de mira de invasores. E eles têm agido com violência. Só na semana passada, dois líderes quilombolas foram assassinados na Bahia (MORAES, 2017). ${ }^{24}$

23 Desde o ano 2004 a ADI 3239/2004 vem tramitando no Supremo Tribunal Federal (STF), tendo seu julgamento retomado várias vezes. Em 8 de fevereiro de 2018, por 10 votos a 1, o Supremo Tribunal Federal (STF) declarou a validade do Decreto 4.887/2003, julgando improcedente a ADI, garantindo, com isso, a titulação das terras ocupadas por remanescentes das comunidades quilombolas. Disponivel em: https:// www.socioambiental.org/pt-br/noticias-socioambientais/em-vitoria-historica-dequilombolas-stf-declara-constitucional-decreto-de-titulacoes. Acesso em: 12 maio 2019.

24 MORAES, Denildo Rodrigues. Ainda há quem nos meça em arroba. Disponível em: 
Conforme denuncia Moraes, a situação das comunidades quilombolas no Brasil é séria e tensa. Ela está atrelada à história de luta contra a opressão e a violência, seja no regime escravagista, em que os conflitos ocorriam por liberdade a existir, seja na atualidade, em que eles se dão pelo direito à posse indevida das terras de quilombos em relação ao poder público e econômico, que mantém formas outras de violência já denunciadas, inclusive assassinatos $^{25}$. Nesse aspecto, as narrativas quilombolas, os movimentos sociais e as entidades parceiras denunciam e anunciam os impactos causados por decisões políticas nas disputas fundiárias dos territórios tradicionais e políticas ambientais excludentes.

Escobar (2015) explica que na Colômbia a articulação coletiva das comunidades afro-colombianas e indígenas negras que compõem os movimentos sociais étnico-territoriais tem como estratégia não apenas a defesa de seus territórios, "mas os fazem em nome de outra concepção de desenvolvimento”. A ancestralidade está intimamente ligada à ocupação histórica de determinados territórios, sendo a continuidade de um mandato ancestral que está presente na memória dos mais velhos e é rememorada por meio da oralidade e do processo histórico de longa data. Para esses movimentos, a ancestralidade é apresentada de outra forma, por meio de modos de produção da vida material e imaterial, de cosmovisão e pensamento que têm sua dimensão de ontologia interligada à defesa vida (ESCOBAR, 2015).

Situando o espaço de corpos étnicos, políticos e geográficos, nos quais diálogos futuros fazem-se necessários, consideramos que as ações das comunidades quilombolas são uma "proposta política-epistêmica" de práxis e valores que se baseiam numa cosmovisão própria, como aponta Escobar (2015). Quando essas comunidades se voltam para a luta em prol de direitos políticos, como a busca pela regularização fundiária ou a luta contra a construção de hidrelétricas, em um processo contínuo e incessante pela conquista de direitos ou contra a cessão daqueles já conquistados, elas não estão lutando somente em prol do território, mas ensinando a todos a pensar nesse meio ambiente com gente, pois quando se trata de território, não é somente a questão ambiental que se deve levar em conta - ela transpassa o território, que, por sua vez, é pensado diferentemente do conceito defendido pelo sistema capitalista.

https://www.socioambiental.org/pt-br/blog/blog-do-isa/ainda-ha-quem-nos-meca-emarrobas. Acesso em: 6 ago. 2017.

250 ano de 2017 (último ano de levantamento) foi o mais violento para as lideranças, somando um total de 14 assassinatos, de acordo com dados da Coordenação de Articulação das Comunidades Negras Rurais Quilombolas (Conaq). Disponível em: https://www.socioambiental.org/pt-br/noticias-socioambientais/violencia-contra168 quilombolas-dispara-em-2017. Acesso em: 20 fev. 2019.

cadernoscenpec 
5. Comunidades QUILOMBOlas: CAMINHO PARA OUTRO CONCEITO DE SOCIEDADE - CONSIDERAÇÕES

Este ensaio se propôs a discutir e analisar os conhecimentos inscritos nas relações das comunidades quilombolas com o território e como táticas de enfrentamento desses povos aos conflitos territoriais e ambientais em que historicamente estão inseridos. Tais relações implicam uma discussão mais ampla no contexto socioeconômico, político e ambiental no sistema capitalista global, por isso encontramos histórico de resistência à opressão, em defesa do território coletivo, em vários países da América Latina. Num contexto local, pontuamos que ao se tratar dos modos de vida inseridos no SATQ, os conhecimentos acumulados são a base da produção de vida em territórios coletivos. Neles ancoram-se as ações e práticas políticas e sociais tanto das comunidades quanto dos movimentos sociais que elas compõem e dos quais participam, constituídos como parte integrante da história nacional, com histórico de resistência para a emancipação e libertação dos grupos humanos. Dessa maneira, esses conhecimentos se configuram como práxis revolucionária e propõem novos olhares e saberes específicos, diferenciados e interdisciplinares para as diversas áreas do conhecimento científico, político e ecológico, apontando para uma sociedade pautada na dignidade humana e no respeito à natureza.

As comunidades do Vale do Ribeira, ao elaborarem um planejamento territorial, como é o caso dos quilombos São Pedro e Morro Seco, nos municípios de Eldorado e Iguape, respectivamente, organizam-se de forma participativa, pensando o território coletivo para as próximas gerações (PASINATO, 2012). Da mesma forma ao realizarem mobilizações contra a construção de UHEs, contra legislações ambientais excludentes que impedem as roças, rechaçando afrontas às conquistas territoriais e outras perdas de direito; ao atuarem para o reconhecimento do Sistema Agrícola Tradicional Quilombola do Vale do Ribeira como patrimônio do Brasil; ao realizarem a feira de troca de sementes e mudas; ao produzirem alimentos sem agrotóxicos, atuando na conservação do bioma Mata Atlântica e ao partilharem seus conhecimentos com a academia. É assim que apontam outro conceito de sociedade possível, pautada em valores anticapitalistas e antirracistas, visando, entre outras demandas, a garantia de direitos fundamentais e essenciais à produção da vida, como educação, saúde, comunicação, segurança e soberania alimentar, defendendo o direito de existir. 


\section{Traditonal quilombolas' knowledge: critical thinking in defense of collective life}

Abstract: The ancient wisdom and knowledges from traditional quilombolas communities in Vale do Ribeira-São Paulo are based in generational transmission by oral tradition, conserved by memory, history, and ethnicity. These knowledges allow a re-interpretation of ancient wisdom, applied and practiced, that are linked to an ancient ethnic territorial worldview, while proponent of a revolutionary praxis by securing and providing autonomy to life in the collective territory. To understand quilombolas' question one must not decontextualise its historical, social, economic, political, cultural, environmental, and epistemic process of resistance from global colonial and capitalistic domination. Quilombolas communities' knowledge proposes changes and critical thinking aiming at human emancipation.

Key words: Quilombos. Collective territory. Ancient wisdom. Preservation of biodiversity. 


\section{Conocimientos tradicionales quilombolas: reflexiones críticas en defensa a la vida colectiva}

Resumen: Los saberes y conocimientos de las comunidades tradicionales quilombolas del Vale do Ribeira (SP) tiene como base la transmisión generacional por medio de la tradición oral, mantenida por la memoria, historia y etnicidad. Tales conocimientos permiten una relectura de los saberes, usos y prácticas que están interconectadas a una cosmovisión étnico-territorial ancestral, proponentes de una praxis revolucionaria, por la seguridad y autonomía a la vida en territorios colectivos. La comprensión sobre la temática quilombola implica en no descontextualizar el proceso de resistencia histórico, socioeconómico, político, cultural, ambiental y epistémico, de la dominación colonial y capitalista global. Los conocimientos de las comunidades quilombolas plantean cambios y reflexiones críticas visando a la emancipación humana.

Palabras clave: Quilombos. Territorio Colectivo. Saberes tradicionales. Conservación de la Biodiversidad. 


\section{REFERÊNCIAS}

ADAMS, C. Sistemas agrícolas itinerantes nas florestas tropicais brasileiras: uma área interdisciplinar de pesquisa. 2014. Tese (Livre-docência) - Escola de Artes, Ciências e Humanidades, Universidade de São Paulo, São Paulo, 2014.

AMÉRICO, Márcia C. Ivaporunduva e Macuanda: estudo etnográfico sobre educação, trabalho e modos de sociabilidade. 2015. 323 f. Tese (Doutorado em Educação) - Universidade Metodista de Piracicaba, Unimep, Piracicaba, 2015.

ANDRADE, Anna Maria; TATTO, Nilto (ed.). Inventário cultural de quilombos do Vale do Ribeira. São Paulo: Instituto Socioambiental, 2013.

BRASIL. Constituição da República Federativa do Brasil. Diário Oficial da União, Brasília, DF, 5 out. 1988. Seção 1, p. 1.

CONSELHO NACIONAL DE EDUCAÇÃO. Câmara da Educação Básica. Texto referência para a elaboração das Diretrizes Curriculares Nacionais para a Educação Escolar Quilombola. Brasília, DF, 2011. p. 37. Disponível em: http://www.google.com.br/url?sa=t\&rct=j\&q=\&esrc=s\&source=web\& $\mathrm{cd}=2 \&$ ved=0CC8QFjAB\&url=http\%3A\%2F\%2Fportal.mec.gov.br\%2Findex. php\%3Foption\%3Dcom_docman\%26task\%3Ddoc_download\%26gid\%3D85 27\&ei=0jzEUevTO4qg7Abnm4CIBg\&usg=AFQjCNF6GvNih7NZO4ctCoX40uq0 IDv84w. Acesso em: 22 ago. 2017.

CUNHA JÚNIOR, Henrique A. Afrodescendência e espaço urbano. In: CUNHA JÚNIOR, Henrique; RAMOS, Maria Estela R. (org.). Espaço urbano e afrodescendência: estudo da espacialidade negra urbana para o debate das políticas públicas. Fortaleza: Edições UFC, 2007. p. 62-87.

DIEGUES, Antonio Carlos. A ecologia política das grandes ONGs transnacionais conservacionistas. São Paulo: Nupaub/USP, 2008.

DUTRA, Mara Vanessa Fonseca. Direitos quilombolas: um estudo do impacto da cooperação ecumênica. Rio de Janeiro: Kononia Presença Ecumênica e Serviço, 2011. p. 20.

ESCOBAR, Arturo. Território de diferença: a ontologia política dos "diretos ao território". Desenvolvimento e Meio Ambiente, v. 35, p. 89-100, dez. 2015. Disponível em: http://revistas.ufpr.br/made/article/view/43540. Acesso em: 27 ago. 2017. 
ESTERCI, Neide. Almanaque Brasil Socioambiental. Instituto Socioambiental (ISA). São Paulo, 2008. Disponível em: https://www.socioambiental.org/ sites/blog.socioambiental.org/files/publicacoes/10297.pdf. Acesso em: 27 de ago. 2017.

GOMES, Nilma Lino. Intelectuais negros e produção do conhecimento: algumas reflexões sobre a realidade brasileira. In: SANTOS, Boaventura de Sousa; MENESES, Maria Paula (org.). Epistemologias do sul. São Paulo: Cortez, 2010. p. 496.

HAYAMA, Andrew Toshio. Unidades de conservação em territórios quilombolas: conflitos socioambientais e atuação da defensoria pública. 2017. 159 f. Dissertação (Mestrado) - Pontifícia Universidade Católica do Paraná, Curitiba, 2017.

MINISTÉRIO DO MEIO AMBIENTE. Despacho 02001.024695/2016-14-Dilic/ Ibama. Indeferimento do pedido de licença prévia para a UHE Tijuco Alto processo 02001.001172?2004-58. Brasília, 2016. Disponível em: https:// www.socioambiental.org/sites/blog.socioambiental.org/files/nsa/arquivos/ document.pdf. Acesso em: 10 maio 2019.

MORAES, Denildo Rodrigues. Ainda há quem nos meça em arroba. 2017. Disponível em: https://www.socioambiental.org/pt-br/blog/blog-do-isa/ ainda-ha-quem-nos-meca-em-arrobas. Acesso em: 6 ago. 2017.

PACHECO, Tania. Desigualdade, injustiça ambiental e racismo: uma luta que transcende a cor. 2007. Disponivel em: http://racismoambiental.net. br/textos-e-artigos/desigualdade-injustica-ambiental-e-racismo-uma-lutaquetranscende-a-cor/. Acesso em: 10.05.2019.

PASINATO, Raquel. Planejamento territorial participativo: relato de experiências em comunidades quilombolas do Vale do Ribeira/SP. São Paulo: Instituto Socioambiental, 2012.

PEDROSO JUNIOR, Nelson et al. A casa e a roça: socioeconomia, demografia e agricultura em populações quilombolas do Vale do Ribeira, São Paulo, Brasil. Bol. Mus. Para. Emílio Goeldi. Ciências Humanas, Belém, v. 3, n. 2, p. 227-252, maio-ago. 2008.

QUIJANO, Anibal. Colonialidade do poder, eurocentrismo e América Latina. In: LANDER, Edgardo (org.). A colonialidade do saber: eurocentrismo e ciências sociais. Perspectivas latino-americanas. Ciudad Autónoma de Buenos Aires, Argentina: Clacso, 2005. (Colección Sur Sur). p. 227-278. 
RATTS, Alex. A face quilombola do Brasil. In: SILVÉRIO, Valter Roberto; MATTIOLO, Érica Aparecida Kawakami; MADIERA, Thais Fernanda Leite (org.). Relações étnico-raciais: um percurso para educadores. São Carlos: Editora da Universidade Federal de São Carlos, 2012. v. 2, p. 133-154.

RIBEIRO FILHO, A. A. Impactos do sistema agrícola itinerante sobre os solos de remanescente de Mata Atlântica com uso e ocupação por comunidades quilombolas do Vale do Ribeira (São Paulo, Brasil). 2015. 387 f. Tese (Doutorado) - Instituto de Biociências, Universidade de São Paulo, São Paulo, 2015.

SÃO PAULO (Estado). Resolução SMA n. 189, de 20 de dezembro de 2018. Estabelece critérios e procedimentos para a exploração sustentável de espécies nativas do Brasil no Estado de São Paulo. São Paulo, dez 2018. Disponível em: https://smastr16.blob.core.windows.net/legislacao/2018/12/ resolucao-sma-189-2018-processo-11895-2013-criterios-e-procedimentospara-exploracao-sustentavel-de-especies-nativas.pdf. Acesso em: 15 maio 2019.

SOUZA, Bárbara Oliveira. Aquilombar-se: panorama histórico, identitário e político do Movimento Quilombola Brasileiro. 1. ed. Curitiba: Appris, 2016.

\section{SOBRE OS AUTORES:}

Márcia Cristina Américo é doutora em Educação pela Universidade Metodista de Piracicaba (Unimep). Atua como pesquisadora independente. Integra a Associação dos Remanescentes do Quilombo de São Pedro (Eldorado-SP).

E-mail: cristinamerico@gmail.com

Luiz Marcos de França Dias é mestrando em Educação pelo Programa de PósGraduação em Educação da Universidade Metodista de Piracicaba e docente na Rede Pública Estadual de Ensino de São Paulo. É bolsista Capes.

E-mail: luizketu@gmail.com

Recebido em: dezembro de 2018

Aprovado em: abril de 2019 